\title{
A Decisão de Abortar: Processo e Sentimentos Envolvidos
}

\section{The Decision to Abort: The Process and Feelings Involved}

\author{
Rosely G. Costa'; Ellen Hardy ${ }^{1,2}$ \\ Maria José D. Osis \& Aníbal Faúndes ${ }^{1,2}$
}

\section{COSTA, R G.; HARDY, R; OSIS, M. J. D. \& FAÚNDES, A. The Decision to Abort: The Process and}

Feelings Involved. Cad. Saúde Públ., Rio de Janeiro, 11 (1): 97-105, Jan/Mar, 1995.

In Brazil, induced abortion is considered a crime in the majority of cases, the result being that there is little official data on the subject. Little is known about the conditions under which abortions are induced This research was designed to shed light on the characteristics of the women who had had an abortion and to study the reasons why and conditions under which it occurred. The sample consisted of all employees $(7,359)$ and students $(2,231)$ in a university program in São Paulo who were mailed a self-administered survey. Accompanying the questionnaire was a letter and self-addressed stamped envelope. $27 \%$ of the employees and $42 \%$ of the students returned the questionnaires. Of these, 1,314 employees and 138 students had had at least one pregnancy. The results presented in this study show that 465 of the employees and students ar some point had thought of having an abortion. They were divided into two groups: those who had had an abortion and those who had nos. The objective was to analyze the association of some characteristics of the women with their decision to have/not have an abortion and how they felt when faced with this decisiva. The proportion of women who had had an abortion was significantly lower among married women than singles. A larger percentage of women who had talked with a friend and/or husband/partner/boyfriend had decided to have an abortion than those who had talked to a parent or had not talked to anyone. More women who said they were not prepared to raiseleducate a child had had an abortion as compared to those giving other reasons. Almost half of the women undergoing an abortion said that they felt bad emotionally and physically afterwards. Among those who had not had an abortion, almost twofifths reported that they felt good, were happy, relieved, and did not regret their decision. The conclusion drawn from the population studied was that emotional and social factors played a signicant role in the decision-making process for women considering an abortion.

Key words: Abortion; Induced Abortion; Women Health; Social Psychology

\section{INTRODUÇÃO}

A questão do aborto provocado freqüentemente é colocada como se a decisão de interromper a gravidez fosse fácil, e a mulher, mais ou menos indiferente a esse ato. Coloca-se o abor-

\footnotetext{
${ }^{\prime}$ Centro de Pesquisas das Doenças Materno-Infantis de Campinas. Caixa Postal 6181, Campinas, SP, 13081-970, Brasil.

${ }^{2}$ Departamento de Tocoginecologia, Faculdade de Ciências Médicas, Universidade Estadual de Campinas. Caixa Postal 6181, Campinas, SP, 13081-970, Brasil.
}

to como uma decisão egoísta da mulher que desafia uma sociedade cujos códigos legais e morais procuram fazer com que ela conserve a gestação de qualquer forma. Assim, a mulher aparece como uma criminosa, que, isoladamente, decidiu cometer um delito (Zugaib, 1990).

Muitas vezes o aborto provocado é visto apenas como problema médico, ficando em segundo plano os aspectos psicológicos e sociais implicados. Isso acontece especialmente em um país como o Brasil, onde o aborto é considerado crime, na maior parte dos casos. Assim, a maioria dos estudos realizados neste país 
foi feita por meio do levantamento de informações hospitalares e concentrou sua análise nos aspectos médicos (Pinotti, 1969; Galbinski, 1971; Boehs et al., 1983).

O resultado dessa visão médica do problema é que faltam dados sobre as circunstâncias sociais e os fatores psicológicos/emocionais que exerceriam alguma influência sobre a decisão de fazer ou não um aborto. Dentro da visão psicanalítica, por exemplo, existem razões inconscientes que podem levar uma mulher a interromper uma gravidez quer de forma espontânea ou provocada (Pines, 1990).

Do ponto de vista social, também se identificam fatores que influenciam a decisão de uma mulher quanto a realizar ou não um aborto. Um estudo feito em Bogotá, com 602 mulheres que tiveram gravidezes não planejadas, mostrou que, embora a gravidez tenha sido inesperada e involuntária, 32,4\% disseram inicialmente que desejavam levá-la a termo. Entretanto, somente $8,6 \%$ pensavam efetivamente em manter a gravidez; quase metade tinha claro que ia interrompê-la, e 43,7\% não sabiam o que fariam. Do total de mulheres, menos de um quinto tomou sozinha a decisão de abortar, sem comunicar sua situação ao companheiro (Villarreal \& Mora, 1992).

Habitualmente pensa-se somente na mulher que aborta, esquecendo-se de que o aborto é apenas uma das conseqüências de um evento que precede necessariamente o ato de abortar: a gravidez indesejada, que ocorre, sem dúvida, com maior freqüência do que a interrupção voluntária da gestação. Frente à gravidez indesejada, o que leva a mulher a decidir pela interrupção ou não da gestação? Quais as influências externas que contribuem para decidir num sentido ou no outro? Uma vez realizado o aborto ou, pelo contrário, decidida a manutenção da gestação, como a mulher se sente física e emocionalmente frente à conduta adotada?

Para contribuir no sentido de entender um pouco melhor as condições em que os abortos são feitos no Brasil, o processo de decisão das mulheres e suas conseqüências, realizou-se em 1990 uma pesquisa com mulheres de uma universidade paulista (Hardy et al.,
1991, 1993; Hardy \& Alves, 1992). Este trabalho analisa a associação de algumas características das mulheres que pensaram em abortar com sua decisão de fazê-lo ou não. Ao mesmo tempo, foram analisadas as manifestações das mulheres sobre como se sentiram frente a essa decisão, fosse a de abortar ou a de não o fazer.

\section{MATERIAL E MÉTODO}

A população-alvo do estudo foi constituída de todas as funcionárias (7359) e alunas de graduação (2231) de uma universidade paulista. Os dados foram obtidos por meio de um questionário auto-respondido, pré-testado em amostra de alunas de graduação e funcionárias de uma das faculdades. Junto com o questionário foram distribuídos uma carta explicando a pesquisa e um envelope carta-resposta comercial para a devolução do questionário. A distribuição desse material às funcionárias foi responsabilidade das chefias de cada departamento. As alunas receberam-no no ato da matrícula para o segundo semestre. Não foi pedida nenhuma informação que permitisse identificar quem respondeu ao questionário, garantindo, assim, o sigilo.

Foram recebidos 1987 questionários respondidos pelas funcionárias $(27 \%)$ e 937 pelas alunas $(42 \%)$, o que correspondeu à amostra espontânea. Os questionários foram revisados, e checada a sua consistência. As respostas foram digitadas duas vezes, por pessoas diferentes, utilizando para isso o módulo de entrada de dados do Statistical Package for Social Sciences (SPSS PC-DE). Corrigiram-se as inconsistências e os erros lógicos. Os dados foram analisados com o SPSS-PC e o Statistical Analysis System (SAS). Para a comparação das características das mulheres que abortaram com as que não abortaram utilizou-se o teste estatístico quiquadrado (Armitage \&.Berry, 1987).

Das mulheres que responderam ao questionário, 1314 funcionárias e 138 alunas tinham tido pelo menos uma gravidez: Este trabalho se refere a 465 dessas funcionárias e alunas que disseram alguma vez ter pensado em fazer aborto. Elas foram divididas em dois grupos, segundo 
a decisão tomada de abortar ou não. Os dados se referem ao último aborto provocado pela mulher ou à última gravidez que ela pensou em interromper.

Muitas mulheres assinalaram mais de uma categoria de resposta em algumas perguntas, como, por exemplo, nas questões: "Com quem conversou para decidir se abortava ou não?" e "Quais as razões para ter pensado em abortar?". Nesses casos, as porcentagens das tabelas correspondentes somam mais de $100 \%$. A análise estatística comparou as mulheres que assinalaram cada categoria de resposta com aquelas que não a mencionaram. Os dados da Tabela 3 foram analisados novamente, comparando-se categorias específicas de resposta, havendo, portanto, as Tabelas 3a e 3b. Nas tabelas são apresentados somente os valores significativos de $\mathrm{p}(<0,05)$.

\section{RESULTADOS}

A proporção de mulheres que pensou em abortar e que efetivamente interrompeu a gravidez foi significativamente menor entre as mulheres casadas do que entre as que tinham engravidado em outro tipo de relacionamento. As cinco mulheres cuja gravidez foi resultado de estupro realizaram o aborto (Tabela 1).
Em relação à(s) pessoa(s) com quem conversaram para decidir se fariam o aborto, significativamente mais mulheres que conversaram somente com namorado/marido/companheiro chegaram a abortar, comparadas com as que conversaram com parentes, outras pessoas ou com ninguém. Também houve diferença significativa ao se comparar as mulheres que conversaram com parentes e outras, pessoas, que abortaram em menor proporção do que as que referiram ter falado com amiga(o) e outras pessoas. Da mesma forma, significativamente mais mulheres que conversaram somente com amiga(o) abortaram, comparadas com as que não conversaram com ninguém (Tabela 2).

No que se refere às razões referidas pelas mulheres para terem pensado em abortar, mais mulheres que disseram não estar preparadas para criar/educar uma criança abortaram, comparadas com as que deram outras razões. Essa diferença foi estatisticamente significativa (Tabela 3a). Entre as mulheres que deram como única razão para pensar em abortar o fato de ser solteira, a proporção de mulheres que abortaram foi menor e significativamente diferente das que mencionaram apenas a razão não estar preparada para criar/educar uma criança (Tabela 3b).

TABELA 1. Porcentagem de Mulheres que Pensaram em Abortar e Chegaram a Fazê-lo, segundo o Tipo de Relacionamento do Qual Surgiu a Gravidez

\begin{tabular}{|c|c|c|c|}
\hline \multirow[b]{3}{*}{ Relacionamento } & \multicolumn{2}{|c|}{ Abortou } & \multirow{3}{*}{$\begin{array}{c}\text { Total } \\
\text { De } \\
\text { Mulheres }\end{array}$} \\
\hline & $\%$ & (n) & \\
\hline & & & \\
\hline Casamento & 55 & (58) & 105 \\
\hline Morava Junto & 80 & (35) & 44 \\
\hline Namoro/Caso & 80 & $(245)$ & 306 \\
\hline Estupro & 100 & (5) & 5 \\
\hline Outro & 80 & (4) & 5 \\
\hline
\end{tabular}

Casamento/demais: $\mathrm{p}<0,0002$ 
TABELA 2. Interlocutor na Tomada de Decisão com Relação ao Aborto. Comparações de Algumas Categorias $^{1}$

\begin{tabular}{|c|c|}
\hline Interlocutor & p-valor \\
\hline \multicolumn{2}{|l|}{ - Parentes somente } \\
\hline Namorado/marido/companheiro somente & 0,05041 \\
\hline \multicolumn{2}{|l|}{ - Parentes e outra pessoas } \\
\hline Namorado/marido/companheiro somente & 0,00012 \\
\hline \multicolumn{2}{|l|}{ - Parentes somente } \\
\hline Namorado/marido/companheiro e outras pessoas & N.S. \\
\hline \multicolumn{2}{|l|}{ - Parentes somente } \\
\hline Amiga(o) somente & 0,00047 \\
\hline \multicolumn{2}{|l|}{ - Parentes e outras pessoas } \\
\hline Amiga(o) somente & 0,00295 \\
\hline \multicolumn{2}{|l|}{ - Parentes somente } \\
\hline Amiga(o) e outras pessoas & 0,00048 \\
\hline \multicolumn{2}{|l|}{ - Ninguém } \\
\hline Namorado/marido/companheiro e outras pessoas & 0,00022 \\
\hline \multicolumn{2}{|l|}{ • Ninguém } \\
\hline Amiga(o) e outras pessoas & 0,00053 \\
\hline
\end{tabular}

${ }^{1}$ Para cada par de categorias, a inferior apresenta-se com maior freqüência do que a superior.

TABELA 3A. Razões Mais Referidas para Terem Pensado em Fazer Aborto, segundo tenham abortado ou não. Em Percentagem

\begin{tabular}{|c|c|c|c|}
\hline \multirow[b]{2}{*}{ Razão } & \multicolumn{2}{|c|}{ Abortaram } & \multirow{2}{*}{$\begin{array}{c}\text { Total } \\
\text { de } \\
\text { mulheres }\end{array}$} \\
\hline & $\operatorname{Sim}^{1}$ & Não ${ }^{2}$ & \\
\hline - Não estar preparada para criar/educar uma criança ${ }^{3}$ & 81 & 19 & 220 \\
\hline - Falta de condições financeiras & 74 & 26 & 180 \\
\hline - Ser solteira & 71 & 29 & 136 \\
\hline - Namorado/marido/companheiro não querer a criança & 76 & 24 & 79 \\
\hline • Família não aceitar & 80 & 20 & 86 \\
\hline Total de Mulheres & 349 & 121 & 470 \\
\hline
\end{tabular}

${ }^{1}$ Faltou informação de duas mulheres.

${ }^{2}$ Faltou informação de três mulheres.

${ }^{3} \mathrm{P}<0,05$ (significativamente diferente do conjunto de mulheres que deram outras respostas). 
TABELA 3B. Razões Mais Referidas para Terem Pensado em Fazer Aborto. Comparações de Algumas categorias $^{1}$

\begin{tabular}{lc}
\hline \hline Razões & p-valor \\
\hline • Não estar preparada (exclusivo) & \\
$\quad$ Ser solteira (exclusivo) & 0,01046 \\
• Não estar preparada & \\
Ser solteira (exclusivo) & N.S. \\
• Não estar preparada (exclusivo) & \\
Ser solteira & 0,00479 \\
\hline \hline
\end{tabular}

${ }^{1}$ Para cada par de categorias, a inferior apresenta-se com maior frequiência do que superior.

Quase metade das mulheres que abortaram disse que depois se sentiu mal emocional e/ou fisicamente $(48,8 \%)$. Nesse caso, foram dadas respostas do tipo: "Muito triste", "Deprimida", "Depois foram nove meses de tortura", "Complexo de culpa", "Infeliz", "Passei muito mal, vomitei, senti tontura", "Tive cólicas", "Um pouco indisposta", "Enjoada", "Mal-estar". Em seguida vieram as que referiram terem ficado bem emocional e/ou fisicamente (27,9\%): "Aliviadíssima", "Sem traumas", "Querendo viver", "Leve e traqüila, pois foi consciente", "Maravilhosamente feliz", "Bem disposta", "Bem clinicamente", "Muito bem fisicamente". Do total de mulheres, $14,7 \%$ deram respostas que expressam tanto sentimentos positivos quanto negativos em relação a ter abortado. Algumas mulheres $(6,1 \%)$ fizeram dissociação entre as sensações físicas e as emocionais (Tabela 4).
Entre as mulheres que não fizeram o aborto, quase dois quintos deram como motivo para isso o medo das consequiências e falta de coragem. Nessa última categoria foram incluídas respostas do tipo: "Tive receio de não dar certo e futuramente trazer complicações", "Medo de ter remorsos", "Não tive coragem", "Concluí que seria muito prejudicial para mim do ponto de vista psicológico", "Era maior o medo do aborto do que de ter um filho". Um terço apontou que resolveu ter o filho ou teve apoio: "Achei que era hora de tomar coragem e enfrentar o problema", "Decidimos que a criança não pediu para nascer e resolvemos ter", "Meu namorado me apoiou e passou a desejar o filho", "Tive muito apoio da minha mãe, irmãs, sogro e amigos", "Eu ia assumir o meu filho casada ou não"., Cerca de $15^{\circ} \%$ referiram a categoria "Companheiro não quis/casamento", que incluía

TABELA 4. Como se Sentiram Depois de Ter Feito o Aborto. Em Percentagem

\begin{tabular}{lc}
\hline \hline Categorias & $\%$ \\
\hline - Mal emocional e/ou fisicamente $^{2}$ & 48,8 \\
- Bem física e/ou emocionalmente & 27,9 \\
- Ambíguo & 14,7 \\
- Bem fisicamente e mal emocionalmente & 4.9 \\
- Bem emocionalmente e mal fisicamente & 1,2 \\
- Não pensaram sobre isso & 0,9 \\
- Outros & 1,5 \\
\hline Total $^{1}$ & 326 \\
\hline \hline
\end{tabular}

${ }^{1}$ Faltou informação de 23 mulheres.

${ }^{2}$ Inclui "arrependida" e/ou "com medo das conseqüências". 
"O pai da minha filha era contra", "Resolvemos reestruturar nossa vida dentro do casamento". Mais de um décimo disse que, embora tenha tentado fazer o aborto, não conseguiu (tentou mas não deu resultado, o médico não quis ou houve falta de condições financeiras), e/ou que a própria mulher ou a família mostrou posição contrária ao aborto: "Considero algo errado", "Não tinha o direito de tirar uma vida", "Por orientação da minha mãe". Um décimo apontou motivos religiosos para não ter feito o aborto. "Por causa da religião", "Busquei a Deus nos meus momentos de angústia e Ele me ajudou", "Sempre me ensinaram que matar é pecado" (Tabela 5).

Do total de mulheres que não abortaram, mais de quatro quintos relataram ter-se sentido bem, feliz, aliviada e não arrependida por não ter feito o aborto. Foram dadas respostas do tipo: "Muito bem emocionalmente"; "Realizada", "A pessoa mais feliz do universo", "Me senti muito aliviada, pois sabia que não era isto que eu queria", "Como se tivesse tirado um peso de cima de mim". Entretanto, 4,3\% disseram ter ficado chateadas, frustradas e arrependidas por não terem feito: "Chateada, se tivesse feito não teria me arrependido", "Muito frustrada, infeliz pela minha falta de coragem", "Muitas vezes me arrependi, talvez se tivesse feito minha vida teria dado outro tomo", "Mal por não ter amparo necessário se por acaso decidisse não ter a criança". A mesma porcentagem expressou simultaneamente sentimentos positivos e negativos em relação a não ter feito o aborto. Seis por cento referiram ter-se sentido culpadas e arrependidas por haver pensado em fazer: "Não gosto nem de lembrar, teria me arrependido se tivesse feito", "Tenho vergonha de mim mesma quando me lembro que eu não queria", "Culpa por ter pensado em realizá-lo", "Sei que vou conviver com isto na consciência o resto da vida", "Um arrependimento muito grande por ter pensado em fazer esse aborto" (Tabela 6).

TABELA 5. Por que Resolveram Não Fazer Aborto. Em Percentagem ${ }^{1}$

\begin{tabular}{lc}
\hline \hline Categorias & $\%$ \\
\hline • Medo das conseqüências/não teve coragem & 39,4 \\
• Resolveu ter o filho/teve apoio & 33,0 \\
• Não conseguiu & 13,8 \\
- Companheiro não quis/casamento & 15,6 \\
• Era contra/família contra & 11,9 \\
• Motivos religiosos & 10,1 \\
• Outros & 2,8 \\
\hline Total & 109 \\
\hline \hline
\end{tabular}

${ }^{1}$ Faltou informação de cinco mulheres, e sete mulheres não estavam grávidas.

TABELA 6. Como se Sentiram por Não Ter Feito o Aborto. Em Percentagem

\begin{tabular}{lc}
\hline \hline Categorias & $\%$ \\
\hline • Bem, feliz, aliviada, não arrependida & 82,9 \\
- Ambígua & 4,3 \\
- Culpada, arrependida por ter pensado & 6,0 \\
- Insegura, com medo, preocupada & 2,6 \\
- Chateada, frustrada, arrependida por não ter feito & 4,3 \\
\hline Total $^{1}$ & 117 \\
\hline \hline
\end{tabular}

${ }^{1}$ Faltou informação de quatro mulheres. 


\section{DISCUSSÃO}

Os resultados desta pesquisa revelam que, frente a uma gravidez indesejada, a mulher precisa sentir que tem uma justificativa muito forte para levar adiante sua intenção de abortar. $\mathrm{O}$ caso mais extremo de justificação é a gravidez resultante de estupro. No extremo oposto, a mulher casada tem mais dificuldade para aceitar a interrupção da gestação do que aquelas que não têm relacionamento com vínculo legal.

Nossos resultados concordam com os de Bohes et al. (1983), que constataram a menor incidência de aborto provocado entre mulheres casadas. A relação conjugal, socialmente legitimada, funcionaria como desestimuladora para se decidir pelo aborto. Além disso, não se pode deixar de associar a esse fator a influência da concepção católica quanto à função procriadora do matrimônio.

Chama a atenção que. o principal motivo associado à maior possibilidade de realizar o aborto tenha sido "não estar preparada para criar um filho", o que não inclui problemas materiais, como dificuldades financeiras ou rejeição do parceiro, que no questionário correspondia a outras categorias de resposta. Aparentemente, essa falta de preparo corresponde mais a um estado emocional ou a uma etapa da vida em que outros projetos pessoais tornar-se-iam incompatíveis com a chegada de um filho. $O$ fato de as dificuldades financeiras não terem sido a razão mais referida pode ser relativizado, porque as alunas dessa universidade são, em geral, de bom nível sócio-econômico. Além disso, mais da metade das funcionárias que responderam ao questionário tinha completado pelo menos um ano de nível superior, o que provavelmente implica ter renda maior do que a da média.

Estes resultados diferem dos de outros autores (Farias, 1972; Bohes et al., 1983; Villarreal $\&$ Mora, 1992), que encontraram os problemas econômicos como razão mais freqüente para ter feito aborto. Essa diferença pode ser explicada pela metodologia diversa utilizada em nosso estudo em relação aos demais. Enquanto no presente estudo a entrevistada respondia anonimamente ao questionário, nas demais pesquisas ela respondia a um(a) entrevistador(a), o que poderia constrangê-la a dar res- postas mais aceitas socialmente como, por exemplo, não ter condições econômicas para ter um filho. O estudo de Villareal, entretanto, também registra que $15 \%$ das mulheres que abortaram justificaram essa conduta por motivos de trabalho, estudo ou algum projeto pessoal que seria frustrado com o nascimento de uma criança.

Respostas de ordem subjetiva, como não estar preparada para criar um filho, são menos justificáveis e mais fáceis de serem admitidas anonimamente. Também quando a entrevistada se sente mais à vontade com o(a) entrevistador(a), pela recorrência de entrevistas, as razões subjetivas afloram. É o caso da pesquisa de Farinã (1975), que encontrou como principal motivo para prática de aborto razões psicossociais, ficando as econômicas em segundo lugar.

A relação positiva entre realizar a intenção de abortar e ter falado com amigo(a) ou parceiro e a negativa no caso de ter falado sobre o assunto com pais ou irmãos sugerem que, enquanto os primeiros provavelmente apóiam outros projetos de vida que não a vinda de um filho, a família próxima valoriza mais o papel de mãe e tende, mais freqüentemente, a influenciar na preservação da gravidez.

A pressão social contra a realização do aborto reflete-se claramente em muitas das respostas: metade daquelas que abortaram sentiu-se mal, física ou emocionalmente, depois do ato; $5 \%$ sentiram-se mal emocionalmente apesar de sentirem-se fisicamente bem; e $15 \%$ manifestaram-se ambigüamente. Isso é corroborado pela expressão de alívio ou felicidade de mais de $80 \%$ das que decidiram não abortar. Mais chamativo do impacto da culpa para a mulher que faz aborto é representado por $6 \%$ delas que, mesmo não havendo realizado a interrupção da gestação, sentiram-se culpadas e arrependidas por terem pensado em fazê-lo.

Assim, nossos achados contradizem aqueles que acusam as mulheres que recorrem ao aborto ou pensam em fazê-lo de serem pessoas frias e insensíveis. Ao contrário, os resultados apresentados revelam o aborto como algo que as sensibiliza profundamente, fazendo-os sofrer física e emocionalmente. $\mathrm{O}$ fato de algumas mulheres terem dado respostas ambíguas em relação a como se sentiram depois de feito o aborto e a 
como se sentiram por não o ter feito indica como essa é uma questão mal resolvida para muitas delas. Nossos resultados coincidem com os de Farinã (1975), que encontrou entre as reações emocionais em consequiência do aborto provocado sentimentos de arrependimento e de remorso.

Por outro lado, $75 \%$ das mulheres que declararam pensar em abortar realizaram essa intenção, e uma de cada oito das que não abortaram não o fez apenas porque fracassou no seu intento. De fato, dois quintos daquelas que não fizeram o aborto deram como motivo para isso o medo e a falta de coragem, e não a decisão de que era a melhor alternativa para elas. A manifestação de alívio por ter continuado a gravidez após ter pensado em abortar, expressa pela grande maioria das mulheres ao preencher o questionário, pode apenas corresponder à dificuldade atual de aceitar o aborto de um filho já nascido no momento da pesquisa e com o qual já existe um elo afetivo, que é incompatível com a expressão de insatisfação por não ter interrompido essa gravidez.

Embora a amostra estudada possa não ser representativa da população, uma vez que, pela metodologia adotada, não foi possível controlar quem respondeu ou não ao questionário, os resultados obtidos são importantes subsídios para refletir sobre a realidade do aborto provocado em nosso país. Eles fornecem indicadores confiáveis do que se passa, porque as respostas foram voluntárias e anônimas.

O presente trabalho serve ainda para desmistificar a idéia de que, se o aborto fosse legalizado, seu número aumentaria muito, porque as mulheres o fariam sem vacilar. Os resultados mostram que a realização do aborto é experiência que traz conseqüências físicas e emocionais ruins para as mulheres e que a decisão de fazê-lo não é inconseqüente. $\mathrm{O}$ aborto é problema sério para as mulheres, mas também para a sociedade que, de certa forma, influencia na sua realização e acaba sofrendo as consequiências em termos de saúde pública e de conflitos sociais. Deve, portanto, ser tratado seriamente, não se dissimulando a sua existência, mas procurando soluções aceitáveis para as mulheres e a sociedade. Nesse sentido é que mais pesquisas sobre o tema e, na seqüência, amplos debates sobre os resultados são necessários e bem-vindos.

\section{RESUMO}

COSTA, R. G.; HARDY, E.; OSIS, M. J. D. \& FAÚNDES, A. A Decisão de Abortar: Processo e Sentimentos Envolvidos. Cad. Saúde Públ., Rio de Janeiro, 11 (1): 97-105, jan/mar, 1995.

No Brasil, o aborto provocado é considerado crime na maioria das vezes, razão pela qual existem poucos dados oficiais sobre o assunto. Pouco se sabe acerca das condições em que é praticado. A pesquisa em questão foi realizada para conhecer as características das mulheres que abortaram e estudar as razões pelas quais o fizeram e as condições em que isso ocorreu. Foi enviado a todas as funcionárias (7359) e alunas (2231) dos cursos de graduação de uma universidade paulista um questionário a ser auto-respondido e devolvido pelo correio. Acompanhava o questionário uma carta e um envelope resposta-comercial. Responderam ao questionário e o devolveram $27 \%$ das funcionárias e $42 \%$ das alunas. Dessas, 1314 funcionárias e 138 alunas tinham tido pelo menos uma gravidez. Os resultados apresentados neste trabalho correspondem a 465 dessas funcionárias e alunas que alguma vez pensaram em fazer aborto. Elas foram divididas em dois grupos, segundo a decisão tomada de faze-lo ou não. O objetivo foi analisar a associação de algumas características das mulheres com a decisão de fazer ou não um aborto e como se sentiram frente a essa decisão. A proporção de mulheres que abortou foi significativamente menor entre as casadas do que entre as que tinham engravidado em outro tipo de relacionamento. Mais mulheres que conversaram com amigo(a) e/ou marido/ namorado/companheiro para decidir se fariam aborto o fizeram, comparadas com as que conversaram com parentes ou não conversaram com ninguém. Mais mulheres que disseram não estar preparadas para criar/ educar uma criança abortaram, comparadas com as que deram outras razões. Quase metade das mulheres que abortaram disse que depois, se sentiu mal emocional ou fisicamente. Entre as que não fizeram o aborto, quase dois 
quintos deram como motivo para isso medo das conseqüências e falta de coragem. Do total de mulheres que não abortaram, mais de quatro quintos relataram ter-se sentido bem, feliz, aliviada e não arrependida disso. Concluiu-se que, na população estudada, os fatores emocionais e sociais tiveram peso significativo no processo de decisão das mulheres de fazer ou não o aborto.

Palavras-Chave: Aborto; Aborto Provocado; Saúde da Mulher; Psicologia Social

\section{REFERÊNCIAS BIBLIOGRÁFICAS}

ARMITAGE, P. \& BERRY, G., 1987. Statistical Methods in Medical Research. Oxford: Blackwell Scientific Publication.

BOEHS, A. E.; SANTOS, E. K. F.; HASSE, M. \& SOUZA, M. L., 1983. Aborto provocado - estudo epidemiológico descritivo numa maternidade de Florianópolis, Santa Catarina. Ciência e Cultura, 35: 501-506.

FARIAS, F. C., 1972. Condicionamentos sócioeconômicos do abortamento provocado. Revista Paulista de Hospitais, 20: 25-31.

FARINÃ, E. B., 1975. Estudo dos motivos, processos e conseqúências do abortamento em população assistida no Pronto-Socorro Obstétrico do Amparo Maternal. Revista da Escola de Enfermagem da Universidade de São Paulo, 9: 323-346.
GALBINSKI, A., 1971. Contribuição ao estudo da epidemiologia do aborto provocado. Jornal Brasileiro de Ginecologia, 71: 201-208.

HARDY, E. \& ALVES, G., 1992. Complicações pós-aborto provocado: Fatores associados. Cadernos de Saúde Pública, 8: 454-458.

HARDY, E.; REBELLO, I.; RODRIGUES, T. \& MORAES, T. M., 1991. Aborto provocado: diferenças entre pensamento e ação. Revista de Ginecologia e Obstetrícia, 2: 111-116.

HARDY, E.; REBELLO, I. \& FAÚNDES, A., 1993. Aborto entre alunas e funcionárias de uma universidade brasileira. Revista de Saúde Pública, 27: 113-116.

PINES, D., 1990. Pregnancy, miscarriage and abortion. A psychoanalytic perspective. International Journal of Psycho-Analysis, 71: 301.

PINOTTI, J. A., 1969. Contribuição ao estudo médico-social das causas determinantes do abortamento provocado. Maternidade e Infância, 28: 09-20.

VILLARREAL, J. M. \& MORA, M. T., 1992. Embarazo Indeseado y Aborto: Determinantes de la lnterrupción del Embarazo no Deseado y Características de las Mujeres que Abortam. Oriéntame. Bogotá: Editorial Presencia.

ZUGAIB, M., 1990. Paradoxos do aborto. Revista de Ginecologia e Obstetrícia, 1: Editorial. 